\title{
GAS FLOW THROUGH POROUS BARRIERS
}

\section{R E C IEINUS

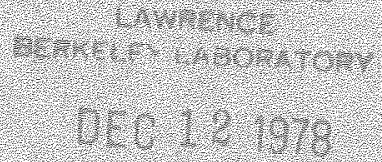

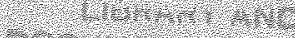

-
Nathan S. Jacobson

(M. S. thesis)

October 1978

Prepared for the U. S. Department of Energy under Contract W-7405-ENG-48
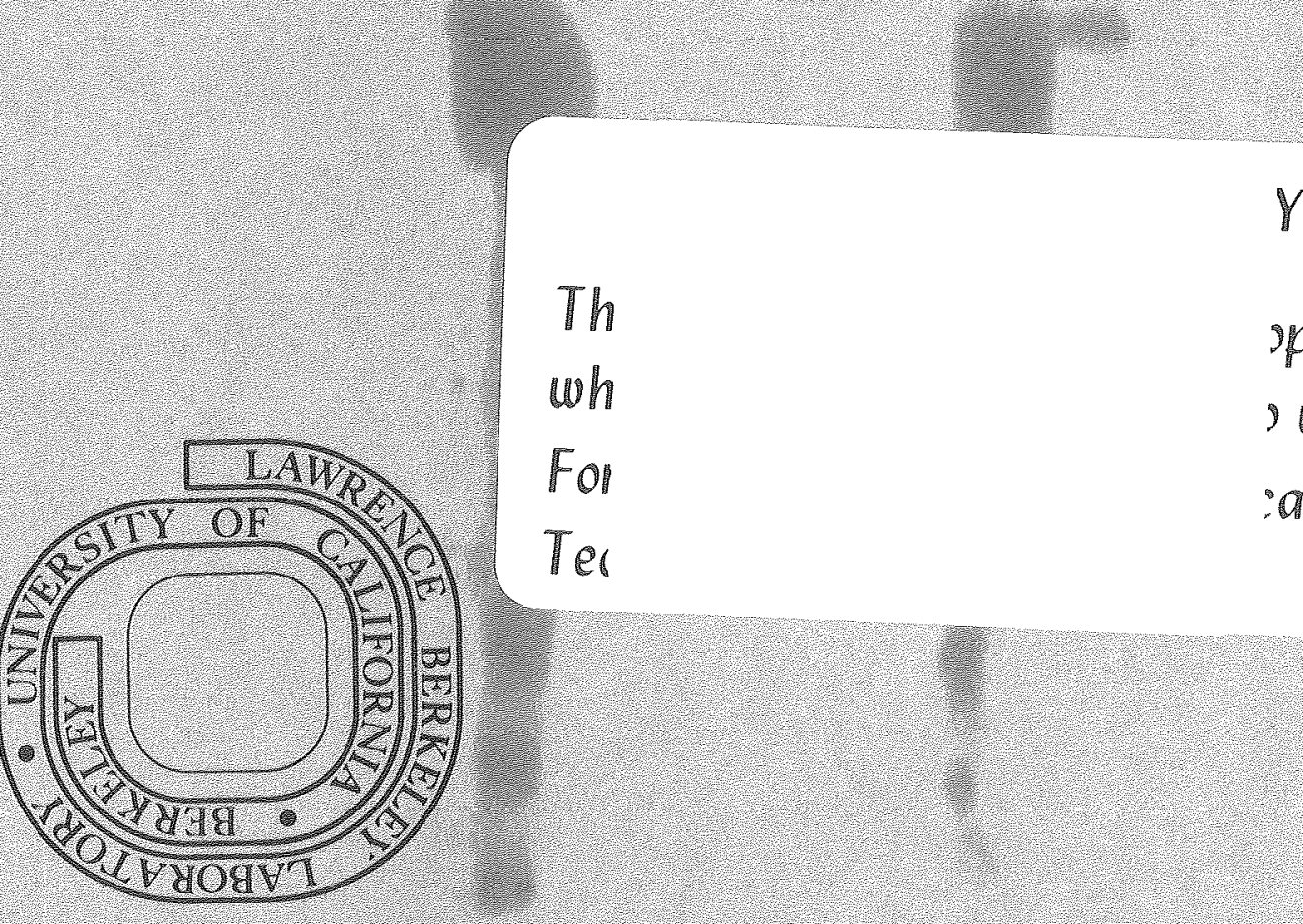

Th

wh

spy

, weeks.

For

Ter

:all 


\section{LEGAL NOTICE}

This report was prepared as an account of work sponsored by the United States Government. Neither the United States nor the Department of Energy, nor any of their employees, hor any of their contractors, subcontractors, or their employees, makes any warranty. express or implied, or assumes any legal liability or responsibilify for the accuracy it. leteness or usefulness of any iniormation, appa ratus, produet or process disclosed, or represents that its use would hot iniringe prvately owned rights:

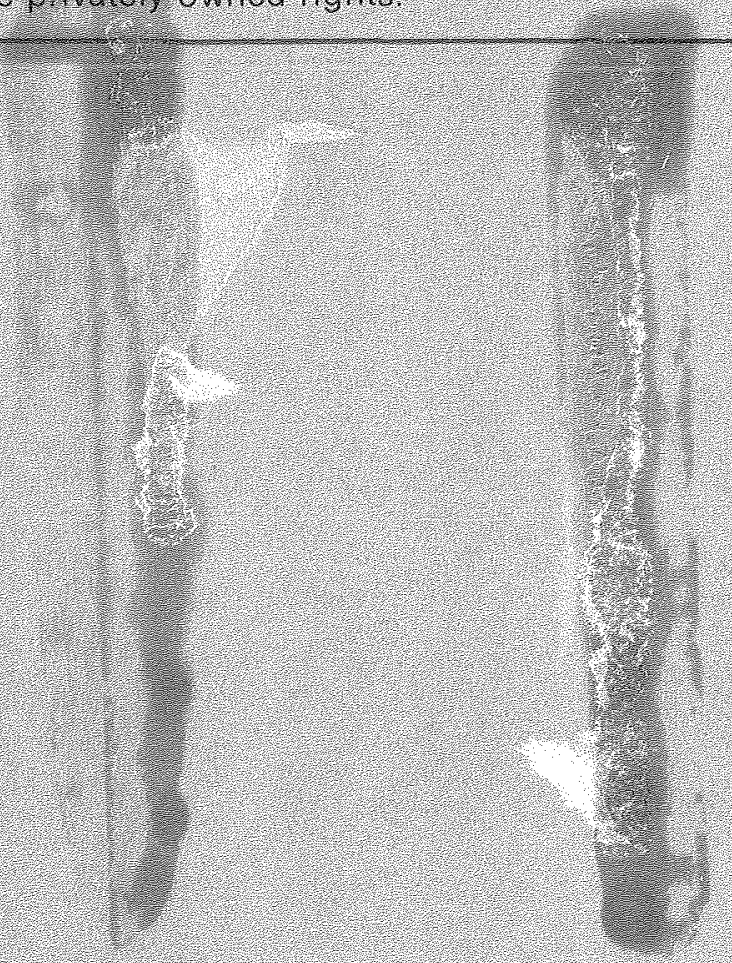


CAS FLOW THROUGH POROUS BARRIERS

Contents

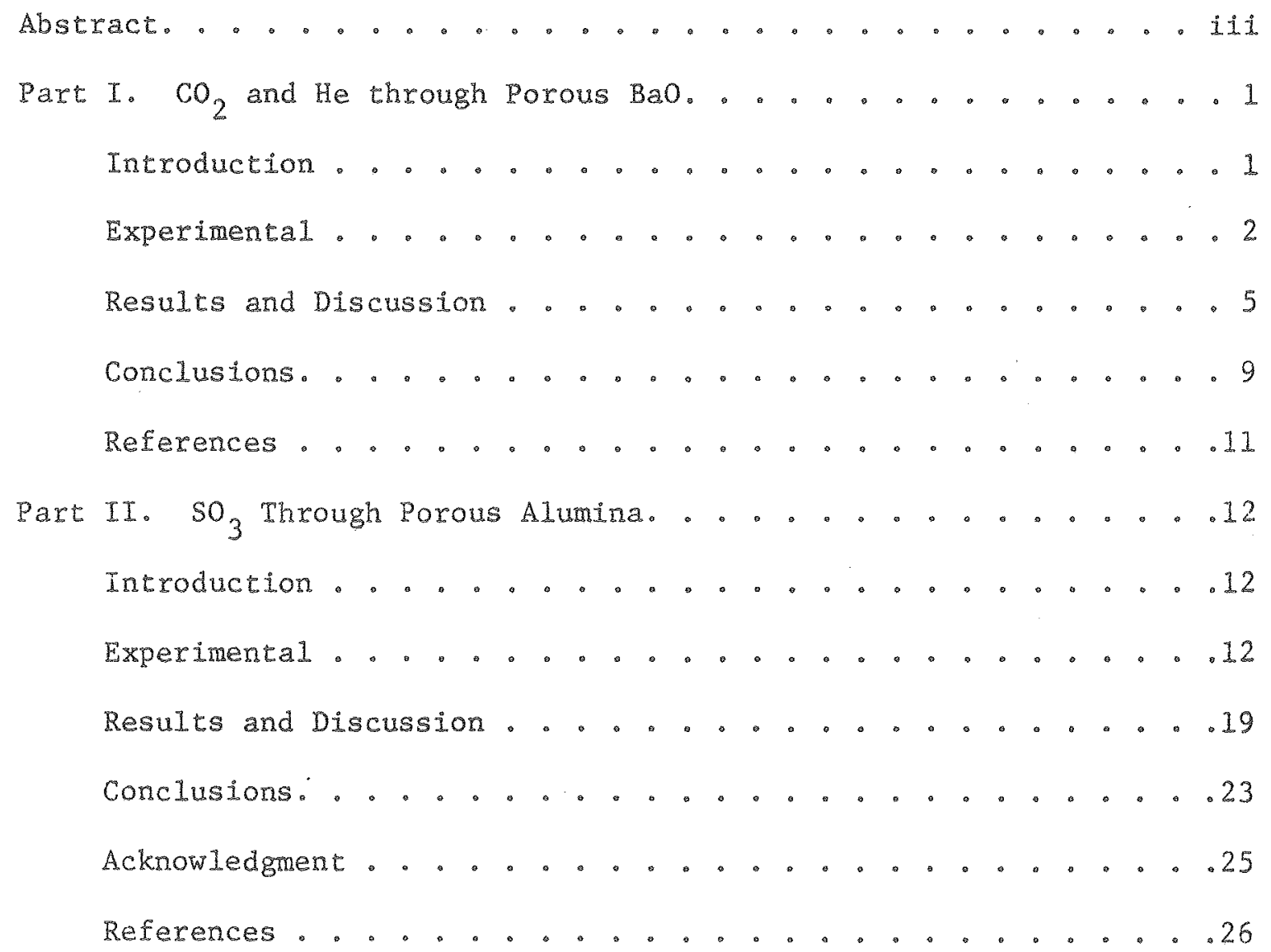





\title{
GAS FLOW TKROUGH POROUS BARRIERS
}

\author{
Nathan S. Jacobson
}

\section{Materials and Molecular Research Division, Lawrence Berkeley Laboratory and Department of Matexials Science and Mineral \\ Engineering, University of California \\ Berkeley, California}

\begin{abstract}
In Part I the possibility of $\mathrm{CO}_{2}$ surface diffusion through the porous $\mathrm{BaO}$ that resules from $\mathrm{BaCO}_{3}$ decomposition is examined. $\mathrm{CO}_{2}$ and He flow rates through a BaO barrier are compared and both are found to exhibit similar behavior. Because He is known not to undergo surface diffusion, it is concluded that $\mathrm{CO}_{2}$ goes through BaO by ordinary Knudsen flow.
\end{abstract}

In Part II the decomposition of $\mathrm{SO}_{3}$ to $\mathrm{SO}_{2}$ and $\mathrm{O}_{2}$ in a porous alumina barrier is studied. The goal is to determine if this reaction will equilibrate in the barriex. A stream of $\mathrm{SO}_{3}$ is run through the barrier and the exit gas compositions are determined as a function of temperature with a mass spectrometer. These compositions are found to differ considerably from the calculated equilibrium values, indicating the reaction does not equilibrate in the barrier. 

Part I. $\mathrm{CO}_{2}$ and he through Porous $\mathrm{BaO}$

\section{INTRODUCTION}

The products of a carbonate decomposition axe $\mathrm{CO}_{2}$ and a porous oxide. In a single crystal decomposition, the porous oxide forms an outer layer and the $\mathrm{CO}_{2}$ must escape through it. One important question is how the $\mathrm{CO}_{2}$ passes through this porous layer. In the pressure range of interest the ratio of the mean free path of $\mathrm{CO}_{2}$ to the oxide pore diameter is large and hence Knudsen flow is the expected mechanism of $\mathrm{CO}_{2}$ transport. However, in a recent theoretical paper, Searcy and Beruto ${ }^{1}$ suggest the possibility that a chemisorbed layer of $\mathrm{CO}_{2}$ forms (as $\mathrm{CO} \frac{\overline{3}}{3}$ ions) and that surface diffusion may be the major mechanism of $\mathrm{CO}_{2}$ transport through the oxide pores.

Differentiating volume flow from surface flow is a problem

addressed by Barrer et $a 1^{2}$ and others ${ }^{3}$. The behavior of a non-adsorbed gas, such as He, is compared to the gas in question. Any additional flow components are assumed to be a consequence of surface diffusion. Such comparisons had apparenty never been made with the porous oxides produced in carbonate decompositions.

In these laboratories, Roberts ${ }^{4}$ studied $\mathrm{CO}_{2}$ and He diffusion through porous $\mathrm{CaO}$. Because the pores of CaO are very small, too small to resolve with the scaming electron microscope (SEM), leakage around the edges of the barrier was feared to be the primary path for gas escape. BaO from the decomposition of $\mathrm{BaCO}_{3}$ has larger pores, so that flow through the barrier was expected to make a larger contribution. relative to leaks. Therefore, the flow of $\mathrm{He}$ and $\mathrm{CO}_{2}$ through porous $\mathrm{BaO}$ were compared in this study. 
In addition, pore diameters were estimated from these flow experiments on the assumption that only Knudsen flow was important. Comparison of these estimated diameters with estimates fron BET surface area measurements and Erom dixect observations of pore dimensions with the SEM corroborated the assumptions made in the flow calculations.

\section{EXPERIMENTAL}

The experimental apparatus consisted of a Nuclide model HT-12-60 mass spectrometer connected to a gas inlet system. The gas inlet system was essentially the same as that described in Part II of this thesis, but was constructed of stainless steel instead of glass and teflon. A $\mathrm{BaCO}_{3}$ disk was mounted on the end of a smooth ground alumina tube in the Knudsen cell chamber of the mass spectrometer. This is shown in Fig. 1. The disks were cut from single crystals of natural barium carbonate (witherite). The impurities, revealed by spectrographic analysis, are Iisted in Table 1. The porous BaO barrier was formed in situ by decomposing these disks of $\mathrm{BaCO}_{3}$ overnight at about $1200^{\circ} \mathrm{K} . \mathrm{CO}_{2}$ evolved was monitored with the mass spectrometer. This in situ decomposition avoided any problems with hydration of the oxide by exposure to the atmosphere.

The gas inlet apparatus allowed selection of efther He or $\mathrm{CO}_{2}$, which was used to fill a ballast tank. The pressure was measured with a Datametrics model 1173 capacitance manometer. A typical experiment was inftiated by filling a ballast tank with the desired gas to a pressure of 100 microns. Next, the ballast tank was opened to the porous barrier and the pressure drop from 100 to 1 um was recorded as a function of time on a strip chart recorder. These experiments were performed at constant temperatures. Temperatures were measured with a chromel-alumel 


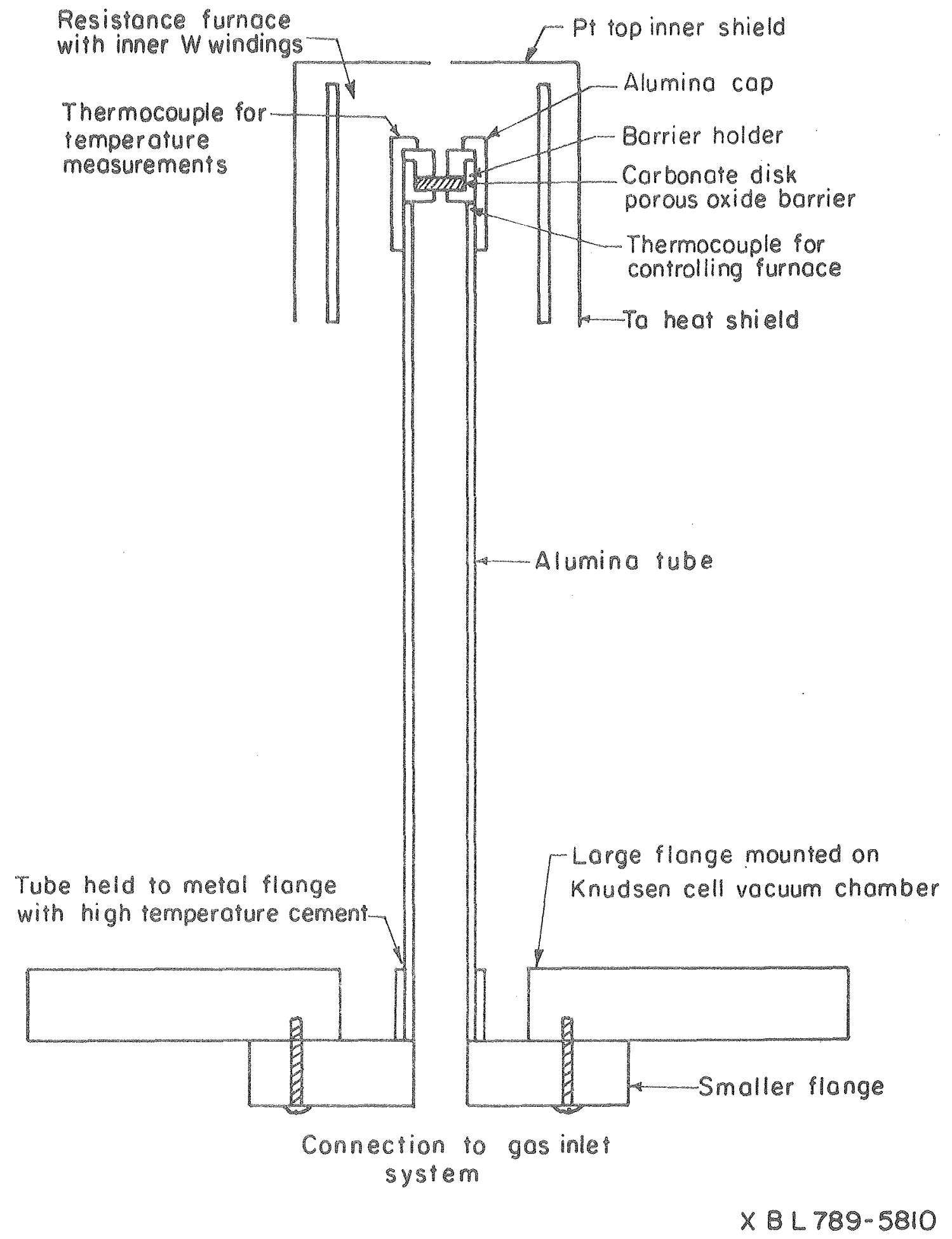

Fig. 1. Porous oxide barrier mount. 
Table 1. Spectrographic Analysis of Barium Carbonate.

\begin{tabular}{cc}
\hline $\mathrm{Ca}$ & $.015 \%$ \\
$\mathrm{Sr}$ & $1 \%$ \\
$\mathrm{Mg}$ & $<.001 \%$ \\
$\mathrm{Al}$ & $<.001 \%$ \\
$\mathrm{Cu}$ & $<.001 \%$ \\
\hline
\end{tabular}


thermocouple located on top of the alumina bartier holder.

An initial experiment was done at room temperature using He and an undecomposed disk. This procedure was assumed to yield the leak rate. Then the carbonate disk was heated to about $1200^{\circ} \mathrm{K}$ and decomposed overnight. High temperature flow rates were measured for both $\mathrm{CO}_{2}$ and $\mathrm{He}$. The leak rate was subtracted from these results. When the sample had cooled to roon temperature, the He flow rates were again measured.

Pore dimensions were estimated from BET surface area measurements and were also observed and measured with the SEM. Problems were encountered with the barium oxide sample hydrating before it could be examined. After some experinentation, an aluminum microscope stage was notched and the decomposed disk was set vertically in the notch. Immediately before placing the disk in the SEM vacum chamber, it was scraped to expose a fresh surface. Insulators generally must be plated with a conductor before SEM examination, but the BaO could be examined without first being plated.

\section{RESULTS AND DISCUSSION}

The flux density $j$ of molecules striking a surface is given by the Hert $z-K n u d s e n-L a n g m u i r$ equation ${ }^{6}: j=\frac{P}{\sqrt{2 \pi M R T}}$ where $P$ is the pressure, $M$ is the molecular weight of the gas, $R$ is the gas constant, and $T$ is the temperature. The product $j A$, where $A$ is the area of the particular surface, gives the number of molecules which strike that surface per unit time: $\frac{\mathrm{dn}}{\mathrm{d} t}=\frac{\mathrm{PA}}{\sqrt{2 \pi M R T}}$. However, in this experiment one has a porous barrier and not all molecules which strike the barrier will pass through. So the area becomes an 'effective area' and the number of molecules per unit time passing through the barrier is given by: $\frac{d n}{d t}=\frac{P A_{e f f}}{\sqrt{2 \pi M R T}}$. 
Now consider the flow of gas from the ballast tank. This is given by the time derlvative of the ideal gas law: $\frac{d n}{d t}=\frac{V_{b}}{R T_{b}} \frac{d P}{d t}$ where $V_{b}$ and $\mathrm{T}_{\mathrm{b}}$ are the volume and temperature of the ballast tank. One now has two expressions for the number of molecules passing through the barrier per unit time, and they can be equated: $\frac{d P}{d t} \frac{V_{b}}{R T_{b}}=\frac{P_{e f f}}{\sqrt{2 \pi R T}}$. Rearranging and Integrating gives the final expression for the effective area: $A_{e f f}=$ $\frac{V_{b}}{R_{b}} \sqrt{2 M R T} \frac{\Delta I n P}{\Delta t}$. As shown by the previous equations, the effective area is directly proportional to the number of molecules which pass through the barxier. Furthermore, it contains a correction for wass and tempexature and thus provides a good basis for comparing He and $\mathrm{CO}_{2}$ flow.

Effective areas are listed in Table 2. A leak run was done with a $\mathrm{BaCO}_{3}$ disk. The effective area for this run was subtracted from the effective areas for each BaO run, yielding the data in the table. The essential feature of these data is that both He and $\mathrm{CO}_{2}$ exhibit similar behavior. $\mathrm{CO}_{2}$ shows no short cixcuit path via surface diffusion. Because He is known not to undergo surface diffusion, it can be concluded that both gases go through the barrier by Knudsen flow.

The primary experimental problem was the leak rate. The porous barrier was press fit, since no adequate high temperature sealent was found. However, using an oxide with large pores and subtracting out the leak rate minimized this problem. Another problem was that the alumina barrier holder reacted slightly with the BaO barrier. This occurred only on the edges and appeared to have no effect on flow through the major portion of the barriex.

Pore diameters were estimated from the flow experiments. If the porous barrier is approximated as a collection of parallel capillaries, 
Table 2. Transmission Properties of $\mathrm{BaO}$ from $\mathrm{BaCO}_{3}$ Decomposition.

\begin{tabular}{|c|c|c|c|c|c|}
\hline Expt. 非 & Material & Temp. ${ }^{\circ} \mathrm{K}$ & Gas & $\begin{array}{l}\text { Eifective Area } \\
110^{4} \mathrm{~cm}^{2}\end{array}$ & $\begin{array}{c}\text { Calculated Diameter } \\
\mu \mathrm{m}\end{array}$ \\
\hline \multirow[t]{4}{*}{1} & $\mathrm{BaCO}_{3}$-leak rate & 701 & He & 1.0 & - \\
\hline & $\mathrm{BaO}$ & 1300 & He & 1.7 & 1.7 \\
\hline & $\mathrm{BaO}$ & 1300 & $\mathrm{CO}_{2}$ & 1.4 & 1.4 \\
\hline & $\mathrm{BaO}$ & 295 & He & 2.8 & 2.8 \\
\hline \multirow[t]{4}{*}{2} & $\mathrm{BaCO}_{3}$-leak rate & 293 & He & 2.5 & - \\
\hline & $\mathrm{BaO}$ & 1316 & He & 1.8 & 2.9 \\
\hline & $\mathrm{BaO}$ & 1316 & $\mathrm{CO}_{2}$ & 1.5 & 2.4 \\
\hline & $\mathrm{BaO}$ & 299 & He & 2.2 & 3.6 \\
\hline \multirow[t]{4}{*}{3} & $\mathrm{BaCO}_{3}$-leak rate & 349 & He & 1.1 & - \\
\hline & $\mathrm{BaO}$ & 1294 & $\mathrm{He}$ & 2.3 & 2.6 \\
\hline & $\mathrm{BaO}$ & 1294 & $\mathrm{CO}_{2}$ & 3.4 & 3.8 \\
\hline & $\mathrm{BaO}$ & 295 & He & 4.4 & 4.9 \\
\hline \multirow[t]{4}{*}{4} & $\mathrm{BaCO}_{3}$-leak rate & 339 & He & 1.7 & - \\
\hline & BaO & 1332 & $\mathrm{He}$ & 1.1 & 1.2 \\
\hline & $\mathrm{BaO}$ & 1332 & $\mathrm{CO}_{2}$ & 2.2 & 2.4 \\
\hline & $\mathrm{BaO}$ & 310 & $\mathrm{He}$ & 1.6 & 1.8 \\
\hline
\end{tabular}


the effective area is given by: $A_{\text {eff }}=n A_{p} \frac{d^{7}}{l}$ where $n$ is the number of capillaries, $A_{p}$ is the cross sectional area of a capillary, and $\frac{d}{l}$ is the clausing factor with d the capillary diameter and l the capillary length. Porosity is defined as the ratio of pore volume to total volume or $\varepsilon=\frac{n A p l}{A l}$ where $A$ is the total area of the barrier's end. Putting this into the expression for effective area gives $A_{e f f}=A \varepsilon \frac{d}{l}$. Fron this expression pore diameters can be estimated. Values are listed in Table 2 .

These pore diameters were compared to pore diameters estimated from surface areas. This method, described by satterfield, ${ }^{8}$ is also based on the assumption of cylinders in the porous medium. The ratio of cylinder volume to cylinder surface area gives the pore radius: $\frac{2 V}{S}=\frac{2\left(n \pi r^{2} l\right)}{(n 2 \pi r l)}$ $=r$ where $n$ is the number of cylinders, $l$ is the cylinder length, and $r$ is the cylinder radius. The volume used in the above equation is the volume of the pores. This can be calculated from porosity and density. Porosity is defined as $\varepsilon=\frac{V_{p}}{V_{p}+V_{s}}$ where $V_{p}$ is the pore volume and $V_{s}$ is the solid volume. For a one gram sample, $v_{S}=\frac{1}{\rho}$ where $\rho$ is the density. Making this substitution and rearranging gives $v_{p}=\frac{\varepsilon}{1-\varepsilon} \frac{1}{\rho}$. So the complete expression for pore radii is $r=\frac{2}{S} \frac{\varepsilon}{(1-\varepsilon)} \frac{1}{\rho}$.

The surface area for a solid with large pores is rather small and BET surface area measurements are not very accurate in this range:

$$
\begin{aligned}
& \text { Measured BET Surface Area } \\
& \qquad \begin{array}{cc}
\mathrm{m}^{2} / \mathrm{gr} & \text { Calculated Diameter } \\
.08 & 11.1 \\
.25 & 3.5
\end{array}
\end{aligned}
$$


However, these results are consistant with pore sizes calculated from 1ow races.

An SEM photograph of the pores is shown in Fig. 2. These pores ranged from 2 to $10 \mathrm{\mu m}$ in diameter, in reasonable agreement with the other data. Because the pores are irregular in shape and the three methods of estimating average pore diameters have different dependences on pore dimensions, closer agreement is not expected.

CONCLUSIONS

The major result of this study is the demonstration that $\mathrm{CO}_{2}$ does not go through BaO by chemisorbed surface diffusion, but rather by ordinary Knudsen flow, much in the same way He goes through BaO. In addition, the pores of BaO were estimated by each of three independent methods to average several microns in diameter.

The possibility still remains that $\mathrm{CO}_{2}$ strongly adsorbs on the porous oxide decomposition product. It is possible that $\mathrm{CO}_{2}$ forms a tightly held chemisorbed monolayer on the oxide and that additional $\mathrm{CO}_{2}$ gas, because it is not strongly bound to the monolayer, goes through the barrier by Knudsen flow. Routh calculations indicate that if a strongly adsorbed monolayer is formed there should be a noticable time delay before $\mathrm{CO}_{2}$ introduced from the high pressure side of the barrier first escapes at the other side. Delay should be especially apparent with an oxide which has very small pores, sich as CaO. Further experiments with a pressure gauge on the exit side of the barrier would test this hypothesis. 


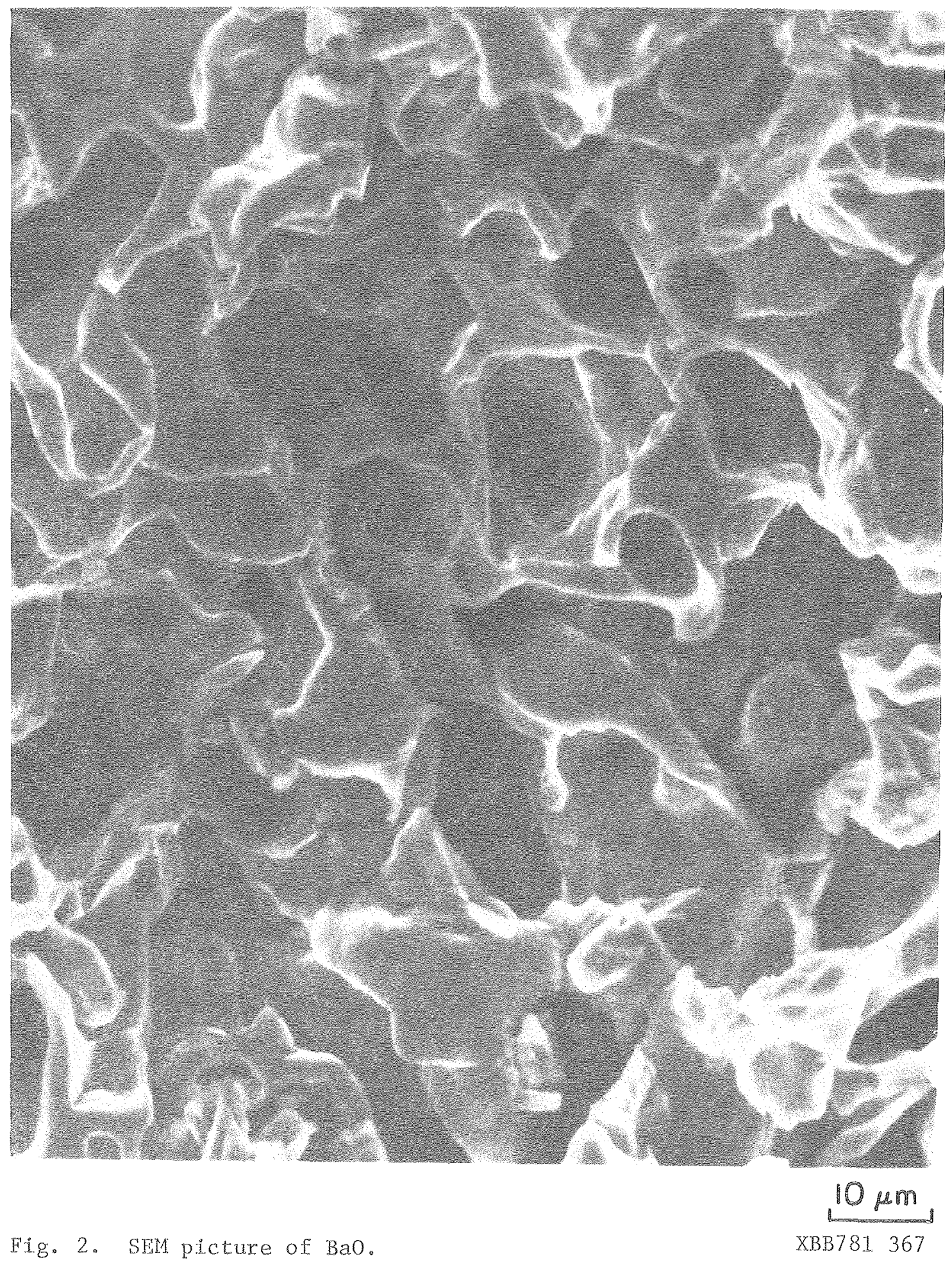


1. A. W. Searcy and D. Beruto, J. Phys. Chem., 82, 163 (1978).

2. R. Ash, R. M. Barrer, J. H. Clint, R. J. Dolphin, and C. L. Murray, R. Soc, (London) Phil. Trans., 275, 255 (1973).

3. C. N. Satterfield, Mass Transfer in Heterogeneous Catalysis, MIT Press, Cambridge, 1970, pp. 47-55.

4. J.A. Roberts, J $x_{0}$, unpublished work, Lawrence Berkeley Laboratory (1977)。

5. T. K. Basu and A. W. Searcy, J. Chem. Soc., Faraday Trans. I, 72, $1889(1976)$.

6. S. Dushman and J.M. Lafferty, Scientific Foundations of Vacuum Technique, 2nd edition, John Wiley \& Sons, Inc., New York, 1962.

7. Op. cit., Ash et al.

8. Op, cit., Satterfield. 
Part II. $\mathrm{SO}_{3}$ Through Porous Alumina

INTRODUCTION

The effect of a porous barrier on a reactive gas mixture has been studied by Searcy and Mohazzabi. ${ }^{1}$ They examined the dimerization of Nacl vapor, a reaction which has a low activation energy. Their results showed the reaction readily reached equilibrium in the barrier.

But suppose a reactive gas mixture with a high activation energy is passed through a porous barrier. The question to be answered then becomes the extent to which the barrier will act as a catalyst and shift the reaction to equilibrium. For this study the decomposition of sulfur trioxide was chosen: $\mathrm{SO}_{3}=\mathrm{SO}_{2}+\frac{1}{2} \mathrm{O}_{2}$. This reaction has a high activation energy and there is currenty considerable interest in the sulfur oxides.

The experiment consisted of passing $\mathrm{SO}_{3}$ at a known inlet pressure through a porous alumina barrier and measuring the exit gas composition with a mass spectrometer. The barrier was varied in temperature from room temperature to about $1000^{\circ} \mathrm{K}$. $\mathrm{SO}_{3}$ to $\mathrm{SO}_{2}$ ratios were measured as a function of temperature and they were compared to the calculated equilibrium $\mathrm{SO}_{3}$ to $\mathrm{SO}_{2}$ ratios. In addition, the experimental $\mathrm{SO}_{3}$ pressure drop was compared to the calculated equilibrium pressure drop.

\section{EXPERIMENTAL}

The apparatus consisted of a Nuclide Model HT-12-60 mass spectrometer and a glass and teflon gas inlet system. A porous alumina bartier was mounced on the end of a mullite tube and heated from room temperature to $1000^{\circ} \mathrm{K}$ in the Knudsen cell chamber of the mass spectrometer. This apparatus is shown in Figs. 1 and 2. 


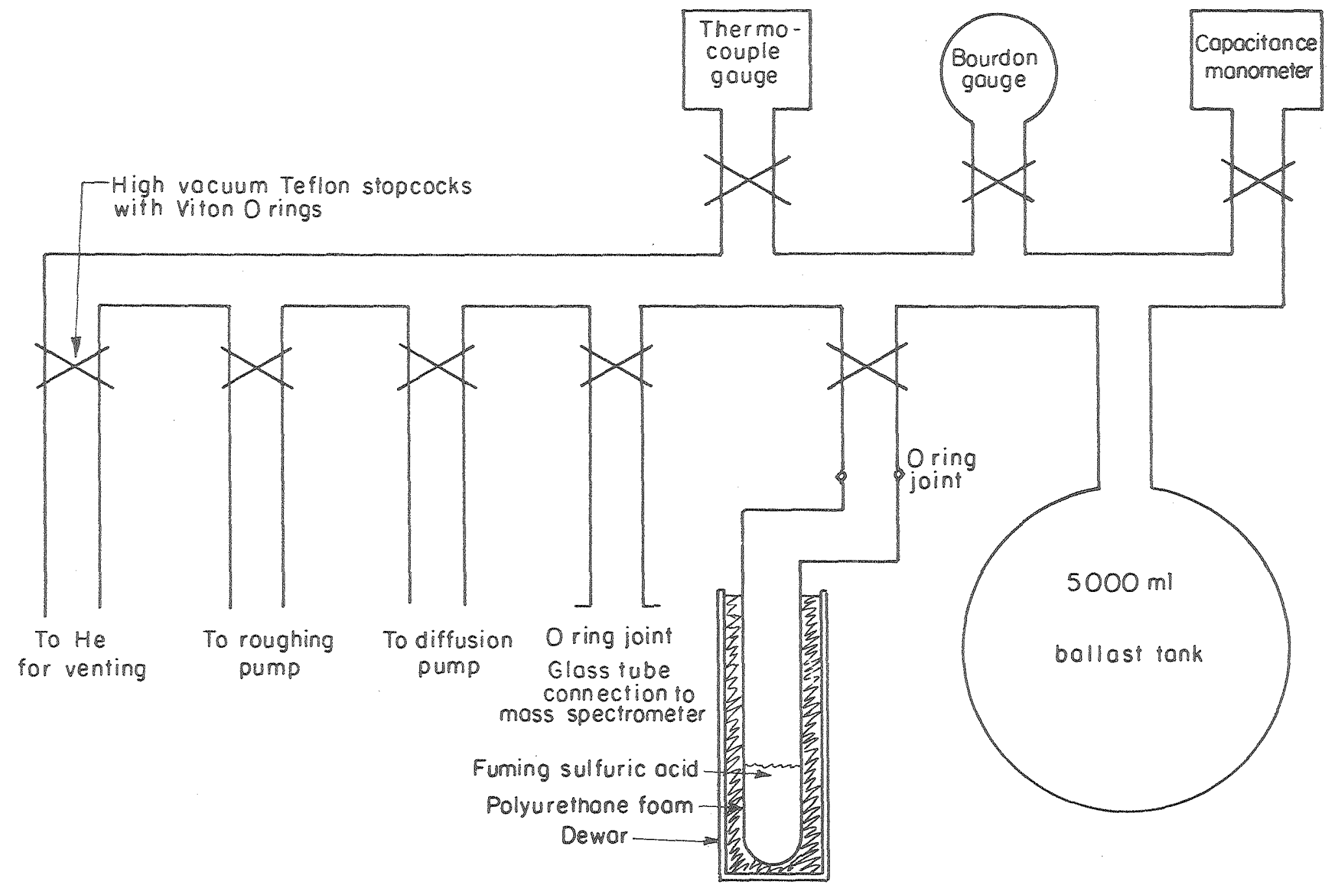

X8L789-5811

Fig. 1. Gas inlet system. 
Mass spectrometer inlet slis

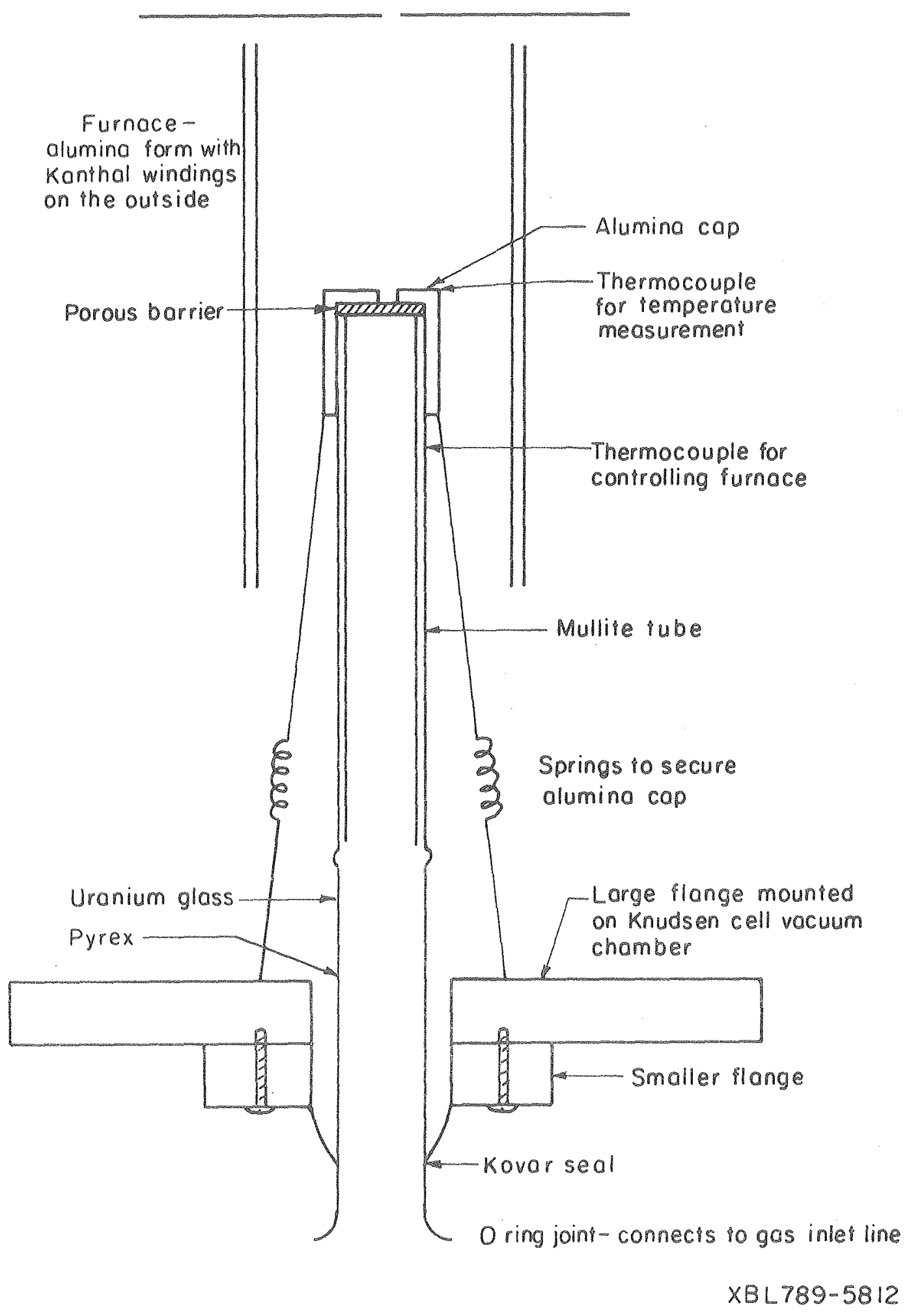

Fig. 2. Porous barrier mount. 
The source of $\mathrm{SO}_{3}$ was the vapor above fuming sulfuric acid. This vapor is almost entrely $\mathrm{SO}_{3}$ and contains negligible water, since water reacts violenty with $\mathrm{SO}_{3^{\circ}}$ Perry's Chemical Engineex's Handbook $^{2}$ gives the vapor pressures of $\mathrm{SO}_{3}$ above fuming sulfuric acid of different strengths. Fuming sulfuric acid is available in three strengths from MCB; the solution 12-18\% free $\mathrm{SO}_{3}$ was found to give the desired inlet pressures of $50-100 \mu \mathrm{m} \mathrm{SO}_{3}{ }^{\circ}$

$\mathrm{SO}_{3}$ is a very corrosive gas. Initially, the stainless steel gas inlet apparatus described in Part I was used. However, when the ballast tank was filled, a steady pressure of $\mathrm{SO}_{3}$ could not be maintained, presumably because $\mathrm{SO}_{3}$ continuously adsorbed on the metal. In addition some $\mathrm{SO}_{3}$ was reduced to $\mathrm{SO}_{2}$; a lower limit on the $\mathrm{SO}_{3}$ to $\mathrm{SO}_{2}$ ratio was set at about 3 with the mass spectrometer. In order to overcome these adsorption and reaction problems, an inert inlet system was constructed, somewhat similar to that of Krishan Lal Luthra. ${ }^{3}$ The system contained no stopcock grease with which $\mathrm{SO}_{3}$ might react. Instead high vacuum stopcocks with o-rings and teflon bodies were used. These are available from Kontes of California. In addition o-ring seals were used for all glass to glass connections.

Obtaining satisfactory o-rings was the major problem in the design of the inlet system. Teflon o-rings will not react significanty with dry $\mathrm{SO}_{3}$ at room temperature, but they are not compressible enough for high vacum applications. The Parker O-Ring Handbook ${ }^{4}$ states that ethylene-propylene ourings are usually satisfactory for use with so 3 , however, these were found to deteriorate rapidly in our $\mathrm{SO}_{3}$ system. Viton O-rings seemed to react somewhat less with $\mathrm{SO}_{3}$, so they were used 
and replaced frequently. It was also found that if the inner 0-rings on the stopcocks (which were exposed to the highest concentration of $\mathrm{SO}_{2}$ ) were removed, adequate glass to teflon seals formed.

$\mathrm{SO}_{3}$ is readily adsorbed at room temperature. Therefore, the entire gas inlet systen was wrapped with heating tape and kept at $120^{\circ} \mathrm{C}$. It was found that when the ballast tank was filled with $\mathrm{SO}_{3}$, a fairly constant pressure could be maintained. With this inlet system a lower Iimit of about 5 could be set on the $\mathrm{SO}_{3}$ to $\mathrm{SO}_{2}$ ratio. This result was a definite improvement over that obtained with the stainless steel system, but the inlet gas was still not pure $\mathrm{SO}_{3}$.

Selection of a pressure gauge for use with $\mathrm{SO}_{3}$ posed a minor difficulty. Nearly every type of pressure gauge contains exposed parts made of metals, which would be corroded by the $\mathrm{SO}_{3}$. After some investigation, it was decided to simply use thexmocouple gauges and replace them frequently. Oddly enough Hastings gauges (which have base metal cases) were found to last longer than Varian gauges (which have stainless steel cases). At the time of writing this thesis, an all glass spiral gauge was located. This gauge, which would be ideal for this study, is available from Electronic Space Products, Inc.

Porous alumina barriers like those of Mohazzabi ${ }^{5}$ were used. They were mounted on the end of a smooth ground mulite tube, as shown in Fig. 2. Two steps were taken to minimize leakage: 1) A thick walled tube was used to lenghten the path through which gas molecules must travel to escape between the porous barrier and the supporting mullite surface. 2) The cap which held the barrier on the tube was spring loaded to maintain a tight fit. 
The end of the tube was positioned in the center of a four inch long furnace. The furnace was arranged to bxing the molecules to temperature before they entered the barrier and to be certain the barrier was in the hottest part of the furnace. However, this put the exit side of the barrier several inches from the mass spectrometer inlet slit. This situation probably contributed to the large background.

This remark concerns the major experimental problem in this study. The information of interest is the flux of $\mathrm{SO}_{3}$ and $\mathrm{SO}_{2}$ that leaves the barrier and travels through a slit to the mass spectrometer ionization chamber. Immediately behind the slit is a shutter. This is a movable metal plate, which can interrupt the molecular beam from the barrier. Molecules which go around the plate are background. However, the difference between the unshuttered and shuttered beam is the $\mathrm{SO}_{3}$ and $\mathrm{SO}_{2}$ flux which leaves the barrier. Generally this should be greater than $50 \%$ for reliable measurements. However, for $\mathrm{SO}_{2}$ the difference was sometimes as 1ow as $5 \%$. This indicates that a large background pressure of $\mathrm{SO}_{2}$ accumulated in our vacum chamber.

Fortunately, background $\mathrm{SO}_{3}$ readily condensed on the walls of the vacuum chamber. At room temperature the difference between the unshuttered and the shuttered $\mathrm{SO}_{3}$ beam was about $85 \%$. When the walls were warmer, the $\mathrm{SO}_{3}$ condensed less and the difference between the unshutcered and shuttered beam was about $45 \%$. These differences are large enough to give reliable $\mathrm{SO}_{3}$ measurements.

The problem then is the large background pressure of $\mathrm{SO}_{2}$. Minor modifications to reduce this pressure were not successful. A cap with a sma11 opening was placed over the porous barriex. It was thought this 
would direct the beam into the slit, but it made no significant difference. A large tantalum heat shield was placed around the barrier. It was hoped that excess $\mathrm{SO}_{2}$ might be pumped off by forming tantalun oxides and sulfides, but this did not occur.

The best solution to the $\mathrm{SO}_{2}$ background problem would be to increase the pumping speed between the barriex and the shuter. This might be accomplished by building a vacuum chamber with walls which are always at liquid nitrogen temperatures, despite the temperature of the barrier. This approach would require major equipment modifications. However, without these modifications, $\mathrm{SO}_{2}$ measurements are of questionable reliability.

A typical expeximent consisted of carefully pumping dow and baking out both the gas inlet system and the mass spectrometer. The gas inlet system was maintained at $120^{\circ} \mathrm{C}$ throughout the experiment. Approximately $5 \mathrm{ml}$ of fuming sulfuric acid were added to a tube, which was connected to the gas inlet system. The air above the tube was slowly pumped off and the entire system was filled with $\mathrm{SO}_{3}$ vapox. The valve to the fuming sulfuric acid tube was left open throughout the experiment. This arrangement provided a constant pressure of between 50 and $100 \mu \mathrm{m}$ for several hours. Temperature was measured with a chromel-alumel thermocouple mounted on the cap which held the barrier in place. Measurements were taken every $50^{\circ}$ from room temperature to about $1000^{\circ} \mathrm{K}$. These measurements were compared to the calculated equilibrium values to decermine if equilibrium had been reached.

$$
\begin{aligned}
& \text { The equilibrium constant for } \mathrm{SO}_{3}=\mathrm{SO}_{2}+\frac{1}{2} \mathrm{O}_{2}{ }^{6} \text { is } \mathrm{K}=\frac{\mathrm{PSO}_{2}{ }^{\mathrm{P}_{2}^{1 / 2}}}{\mathrm{P}_{\mathrm{SO}_{3}}}
\end{aligned}
$$


$\log K=8.8557-\frac{5465.5}{\mathrm{I}}-1.21572 \log \mathrm{T}$. Suppose one has a known inlet pressure of $\mathrm{SO}_{3}$ :

$\mathrm{K}=\frac{\mathrm{p}_{\mathrm{SO}_{2}}^{\left(1 / 2 \mathrm{PSO}_{2}\right)^{1 / 2}}}{\mathrm{p}_{\mathrm{SO}_{3}}^{\mathrm{in}}-\mathrm{p}_{\mathrm{SO}_{2}}}$ or $\mathrm{p}_{\mathrm{SO}_{2}}^{3}-2 \mathrm{Kp}_{\mathrm{SO}_{2}}^{2}+4 \mathrm{Kp}_{\mathrm{SO}_{3}}^{\mathrm{in}} \mathrm{p}_{\mathrm{SO}_{2}}-2 \mathrm{Kp}_{\mathrm{SO}_{3}}^{\mathrm{in}}{ }^{2}=0$

This polynomial was solved for $\mathrm{P}_{\mathrm{SO}_{2}}$ using an inlet pressure of $\mathrm{p}_{\mathrm{SO}_{3}}^{\text {in }}=$ $70 \mu \mathrm{m}$, every $10^{\circ}$ from $300^{\circ}$ to $1300^{\circ} \mathrm{K}$. The polynomial root finder MULLERC in the CERN computex library was used. In addition the equilibrium pressures of $\mathrm{SO}_{3}$ and the $\mathrm{SO}_{3}$ to $\mathrm{SO}_{2}$ ratios were calculated. These values are only approximations. The inlet stream was not $100 \% \mathrm{SO}_{3}$ and we have not considered the pressure gradient through the barrier. However, we are making a rough comparison to major compositional changes over a wide range of temperatures, so approximate equilibrium values are all that are necessary.

\section{RESULTS AND DISCUSSION}

Initially we planned to compare experimental $\mathrm{SO}_{3}$ to $\mathrm{SO}_{2}$ ratios to calculated equilibrium $\mathrm{SO}_{3}$ to $\mathrm{SO}_{2}$ ratios. In order to obtain the experimental ratios, we needed to correcty interpret the mass spectra of $\mathrm{SO}_{3}$ and $\mathrm{SO}_{2}$. The difficulty here is that $\mathrm{SO}_{2}^{+}$is formed both as the parent ion of $\mathrm{SO}_{2}$ and a fragment ion of $\mathrm{SO}_{3}$. There are two approaches to the problem that results. One approach is to establish a mass spectroneter Eragmentation pattern for $\mathrm{SO}_{3}$, but this was not possible because we did not have a source of pure $\mathrm{SO}_{3}$. Another approach, used by Lau, Cubicciotti and Hildenbrand, ${ }^{7}$ is to turn down the energy of the Lonizing electrons to $17 \mathrm{eV}$ so the $\mathrm{SO}_{3}$ does not fragment. However, the resultant signals were very weak and our instrument had too much noise to give reliable readings. Therefore, we decided to use $70 \mathrm{eV}$ ionizing 
electrons and simply regard the $\mathrm{SO}_{3} \mathrm{to} \mathrm{SO}_{2}$ xatio as a lower limit. This was acceptable because we were looking for large changes in the $\mathrm{SO}_{3}$ to $\mathrm{SO}_{2}$ ratios.

The reaction of $\mathrm{SO}_{3}$ and the alumina barxier to form $\mathrm{Al}_{2}\left(\mathrm{SO}_{4}\right)_{3}$ needs to be considered: $\mathrm{Al}_{2} \mathrm{O}_{3}(\alpha)+3 \mathrm{SO}_{3}(\mathrm{~g})=\mathrm{Al}_{2}\left(\mathrm{SO}_{4}\right)_{3}(\mathrm{~s})$. At lower temperatures the production of $\mathrm{Al}_{2}\left(\mathrm{SO}_{4}\right)_{3}$ is quite strongly favored, but $\mathrm{SO}_{3}$ pressures were little changed on passing through the porous alumina barrier. Thus the $\mathrm{SO}_{3}$ probably reacts with $\mathrm{Al}_{2} \mathrm{O}_{3}$ to form a prom tective coating of $\mathrm{Al}_{2}\left(\mathrm{SO}_{4}\right)_{3}$. Above $780^{\circ} \mathrm{K}$ the equilibrium pressure of $\mathrm{SO}_{3}$ from $\mathrm{Al}_{2}\left(\mathrm{SO}_{4}\right)_{3}$ decomposition drops well below $100 \mathrm{\mu m}^{8}$ and the decomposition of $\mathrm{SO}_{3}$ can proceed unhindered. Thus the data from $780^{\circ} \mathrm{K}$ to $1000^{\circ} \mathrm{K}$ is of primary interest.

Table 1 shows the experimental and calculated equilibrium $\mathrm{SO}_{3}$ to $\mathrm{SO}_{2}$ ratios for a porous barrier. These data are plotted in Fig. 3. The essential feature is that the experimental ratios show relatively little change compared to the equilibrium ratios. Thus it is quite probable that the reaction is not equilibrating in the bartier. Note that the absolute $\mathrm{SO}_{2}$ peak intensity increases and the difference between the unshuttered and shuttered $\mathrm{SO}_{2}$ beam becomes small at higher temperatures. This is due to the accumulation of $\mathrm{SO}_{2}$ in the ion chamber, a problem discussed previously. Fortunately, our conclusion can be verified by another approach.

The difference between the unshuttered and shuttered $\mathrm{SO}_{3}$ beam was 85 to $45 \%$ throughout the temperature range and therefore should yield reliable measurements. A good test for equilibrium is to see if the experimental $\mathrm{SO}_{3}$ pressure drops as rapidly as the calculated equilibrium 
Table 1. SO $_{3}$ through a .8m Thick Porous Barrier.

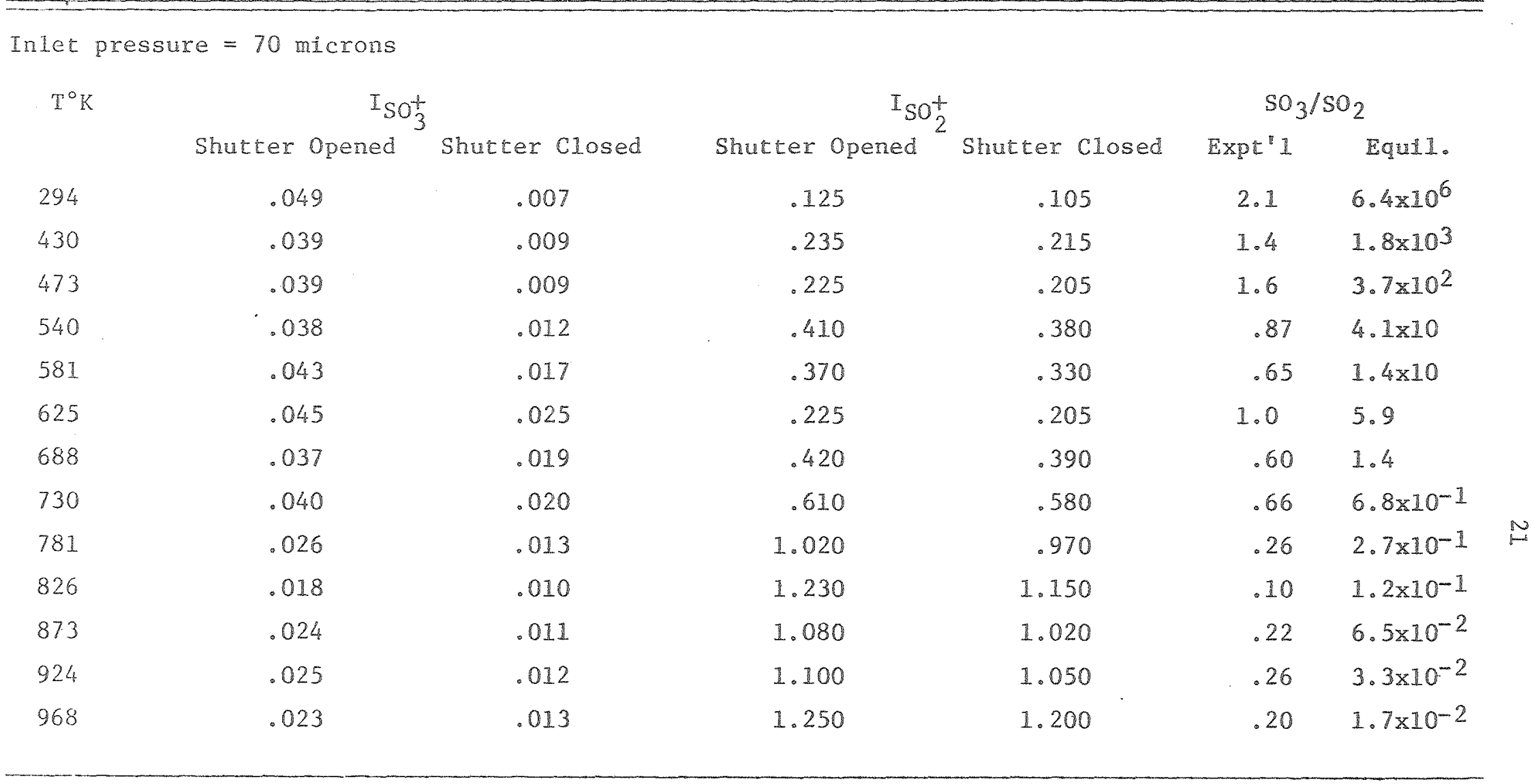




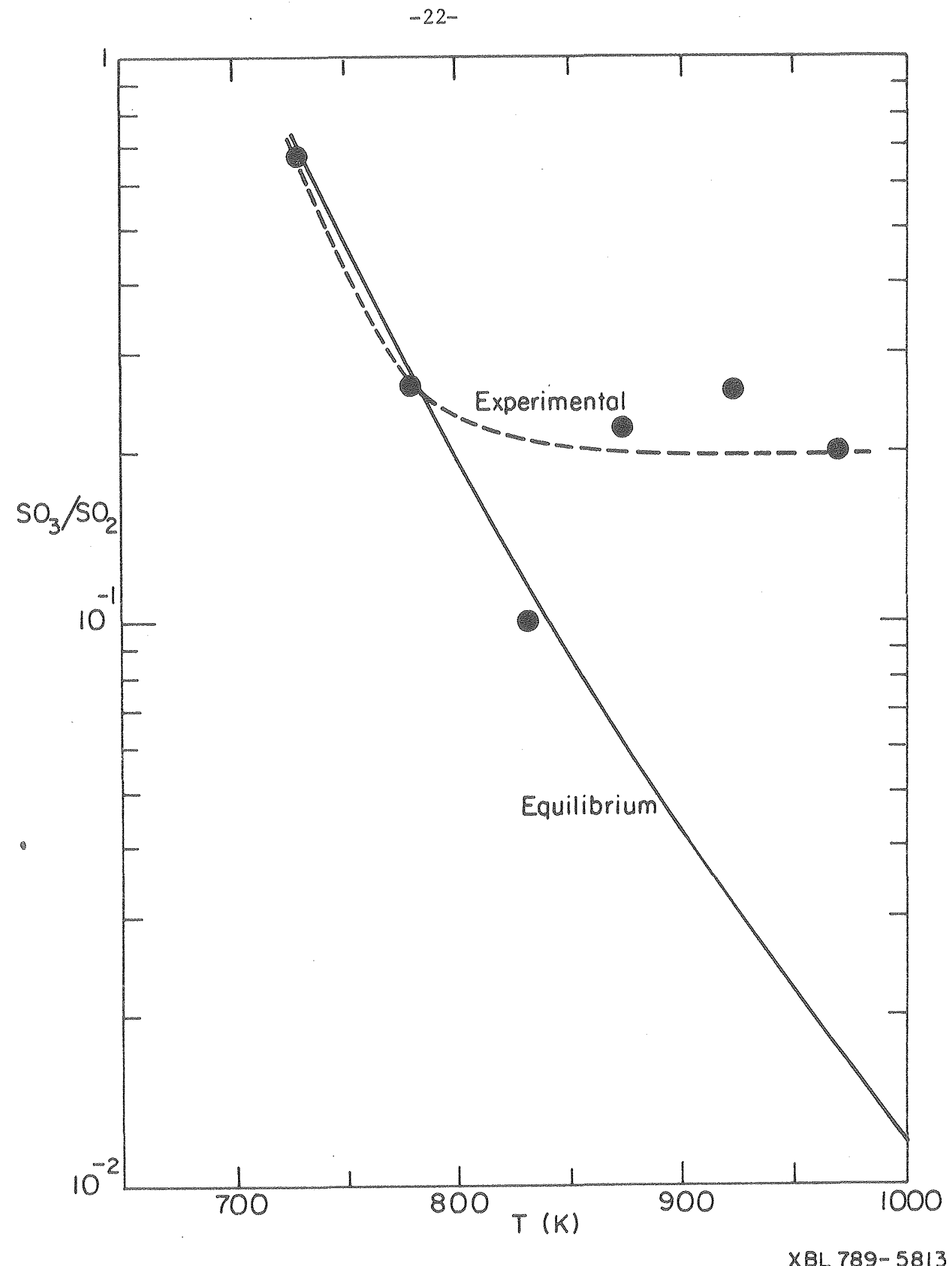

Fig. 3. $\mathrm{SO}_{3}$ to $\mathrm{SO}_{2}$ ratios. 
$\mathrm{SO}_{3}$ pressure on raising temperature. Pressure is related to mass spectromerer intensity by $\mathrm{P}=\mathrm{kIT}_{\mathrm{T}}{ }^{9}$ where $\mathrm{P}$ is the pressure, $k$ is the machine constant, I is the intensity, and $T$ is the temperature. Figure 4 shows a plot of IT Vs. $\mathrm{T}$ and a plot of calculated equilibrium pressure vs. T. The expeximental $\mathrm{SO}_{3}$ pressure changes only slightly as compared to the equilibrium $\mathrm{SO}_{3}$ pressure. This verifies the conclusion reached Erom $\mathrm{SO}_{3}$ to SO ratios - - the reaction does not equilibrate in a porous alumina barcier.

\section{CONCLUSIONS}

It has been shown that the decomposition of $\mathrm{SO}_{3}$ does not equilibrate in a porous alumina barrier. This is expected, since alumina is generally not a catalytically active material.

Before continuing this study, it would be best to modify the apparatus so more reliable $\mathrm{SO}_{2}$ measurements could be made. These modifications involve increasing the pumping speed between the porous barrier and the nass spectrometer inlet slit. The next step would be to examine catalytically active porous barriers, such as $\mathrm{Fe}_{2} \mathrm{O}_{3}$ or Pt. These barriers should push the reaction closer to equilibrium. 


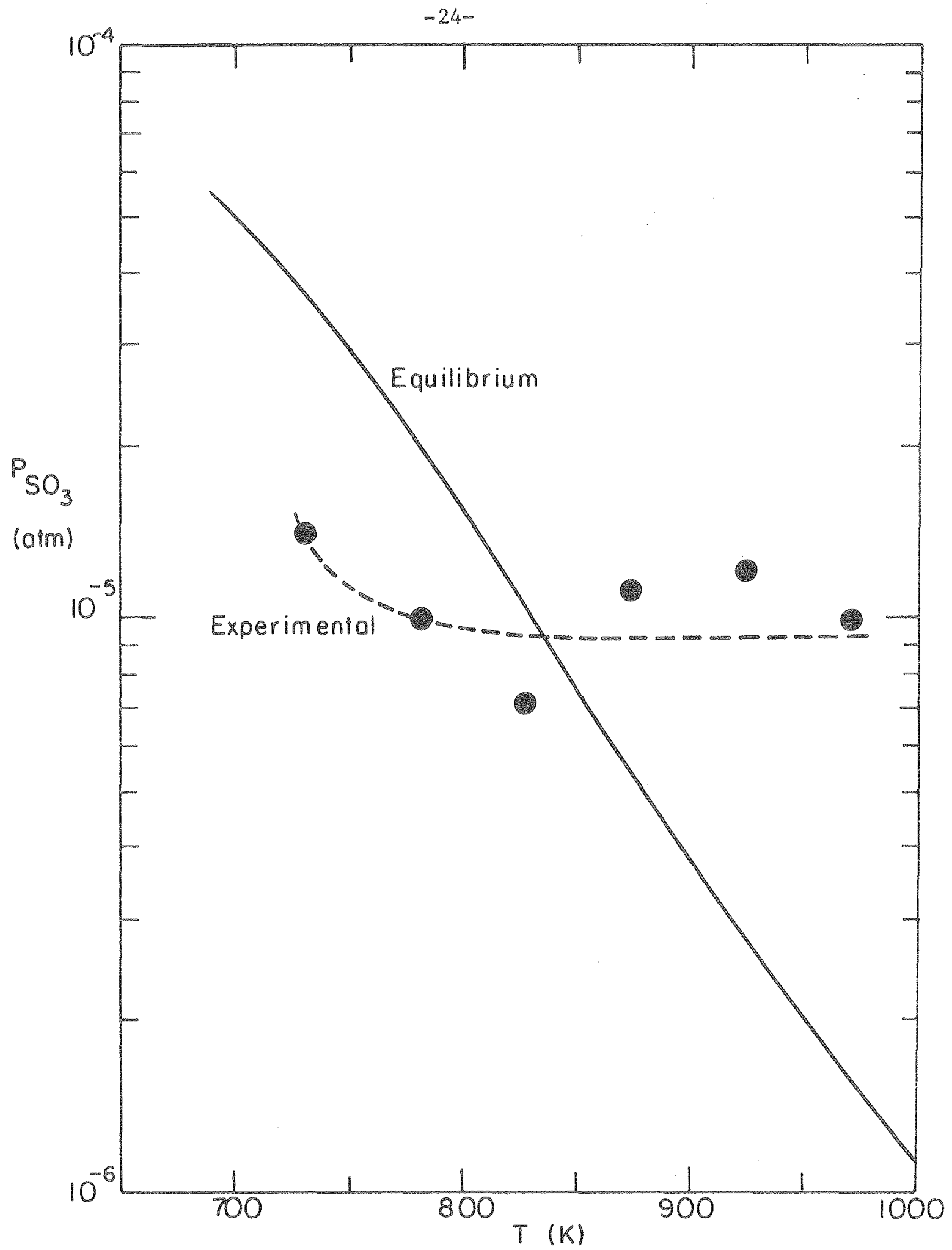

XBL $789-5814$

Fig. 4. $\mathrm{SO}_{3}$ pressure drop. 
ACRNOWLEDGMENT

I am very grateful to Professor Alan W. Searcy for his guidance and kind encouragement throughout this study. A very special 'thank you' is due to Dr. James A. Roberts, Ir. for instruction in the use of the mass spectrometex and his Frequent advice throughout this study. Dr. David Meschi also provided much useful advice. Professor Searcy's laboratories have a particularly fxiendly and pleasant atmosphere to work in - all of the members of his group are to be thanked for this.

The technical staff at LBL provided invaluable aid. Thanks are particularly due to Emory Kozak and the LBL glass and ceramic shops. I am grateful to Gay Brazil for typing this material.

This work was supported by the Division of Materials Sciences, Office of Basic Energy Sciences, U.S. Department of Energy. 


\section{REFERENCES}

1. P. Mohazzabi and A. W. Searcy, J. Chem. Phys., 65, 5037 (1976).

2. J.H. Perry, R. H. Perry, C. H. Chilton and S. D. Kirkpatrick, eds. Perry's Chemical Engineers' Handbook, Fourth edition, McGraw Hill, New York, 1963, p。 3-26.

3. Krishan Lal Luthra, Ph.D. Thesis, University of Pennsylvania.

4. Parker Seal Co., Parkex O-Ring Handbook, 1977, p. B26.

5. Op. cit., Mohazzabi.

6. R. D. PehIke, Unit Processes of Extractive Metallurgy, American Elsevier, New York, 1973, p. 288.

7. K. H. Lau, D. Cubicciotti, and D. L. Hildenbrand, J. Chem. Phys., 66, $4532(1977)$.

8. K. H. Stern and E. L. Weise, National Bureau of Standards Report NSRDA-NBS 7, U.S. Government Printing Office, Washington, DC, 1966.

9. R. T. Grimley, in The Characterization of High Temperature Vapors, John Wiley \& Sons, New York, 1967, p. 225. 
This report was done with support from the Department of Energy: Any conclusions or opinions expressed in this report represent solely those of the author(s) and not necessarily those of the Regents of the University of California, the Lawrence Berkeley Laboratory or the Department of Energy. 


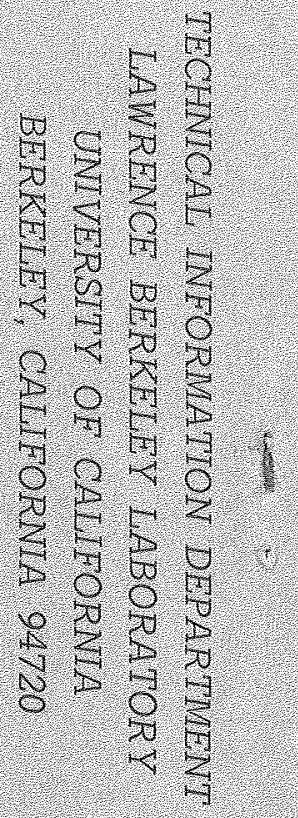

